\title{
Postural Comparison of Dextrous and Ambidextrous Players
}

\author{
${ }^{1}$ Dr. Suresh Kutty.K and ${ }^{2}$ Bintu.T.Kalyan
}

\begin{abstract}
The purpose of the study was the postural comparison of dexterous and ambidextrous players. Human posture is the basic thing that a sports man need for his sports performance at an optimum level. Each and every human beings posture will build up according to the nature of activity.

The purpose of the study was to analyze the postural deformities between dexterous and ambidextrous players. The subjects were selected from the Kannur university campus, Christ College Irinjalakuda, $S N$ College Kannur, LNCP Trivandrum, Calicut University Center for Physical Education, ST.Thomas college Pala and ST.Thomas college Thrissur, the investigator go and collect data from the players. The total number of hundred $(N=100)$ players and the fifty $(n=50)$ from the each group. The investigator was given a small description about the test and it's important to the subjects. The New York posture rating scale was utilized for the posture assessment. Depending up on the deformity, the players were ranked according to the specific norms of the test like 5 for good posture, 3 for average, 1 for poor posture. After taking the raw scores of the students, calculate the percentage of postural deformity by using independent ' $t$ ' ratio.

From the finding we would make understand that the ambi-dexterous players show comparatively good posture than the dexterous players. Posture of the cricket players was the most fatly than the other players. In the case of the anterior postural region cricket players and the lateral postural region the volley ball players had the poor postural level as compared to the other players. The swimmers had the good posture among the anterior and lateral region of posture.
\end{abstract}

\section{Introduction}

In sports and games, different types of movements are there. In some games the players use their one side of the body predominantly. In the case of a right hand bowler in cricket, his right hand side is stronger than the left hand side because he needs to use his right side to perform the skill. The continuous use of the hand is leads to developing strong muscles on that particular area. These developments are causes to imbalance between muscles on the basis of its strength. In the case of a right arm fast bowler, his right deltoid muscles are stronger than the left side, and left oblique muscles are stronger than the right side. This improper toning of the muscles is slowly leads to the improper alignment of the spine. .E.g.: Badminton, cricket, javelin throw. In sports like weight lifting and swimming both hand come into play. So the both side of our body get equal strength. In the case of swimming, the swimmer uses his both hands equally for the execution of the skill. In this case his body gets equal strength on each side. This study aims to take postural comparison between the players who are using their one side of the body and the players are using their both side equally. In sports and games, different types of movements are there. In some games the players use their one side of the body predominantly. In the case of a right hand bowler in cricket, his right hand side is stronger than the left hand side because he needs to use his right side to perform the skill. The continuous use of the hand is leads to developing strong muscles on that particular area. These developments are causes to imbalance between muscles on the basis of its strength.

\section{Methodology}

The subjects were selected from institutions namely School of Physical Education and Sports Sciences , Christ College Irinjalakuda, S N College Kannur, M A college kothamangalam, Calicut University center, ST.Thomas college palai, Malabar Christian college Kozhikkod, ST.Thomas college thrissur and ST. Pius college Rajapuram. The investigator visited their institutions personally and collects the data. The total number of subjects was hundred $(\mathrm{N}=100)$ and 50 each $(\mathrm{n}=50)$ from both dexterous and ambidextrous male players. Each group consist five sub-groups $(n=10)$ of different games with respect to the dexterity and ambidexterity. Body posture was selected as the criterion variable for the study. New York postural test* was utilized for measuring the posture of selected players.

\section{Statistical technique:}

Independent' $t$ ' test will be utilized for comparing the mean difference between dexterous and ambidextrous players on their posture.

\footnotetext{
${ }^{1}$ Associate Professor, School of Physical Education and Sports Sciences, Kannur University
}

${ }^{2}$ MPhil Scholar, School of Physical Education and Sports Sciences, Kannur University 


\section{Results And Discussion}

Table No 1 Total score of anterior posture grade of selected players.

\begin{tabular}{|l|l|}
\hline Badminton & 240 \\
\hline Cricket & 162 \\
\hline Hand Ball & 204 \\
\hline Throwers In Athletics & 177 \\
\hline Volly Ball & 210 \\
\hline Weight Lifters & 300 \\
\hline Power Lifters & 300 \\
\hline Body Builders & 300 \\
\hline Runners & 286 \\
\hline Swimmers & 300 \\
\hline
\end{tabular}

From the table 1, it is clear that the ambidextrous players (last five) scored more than the dexterous players (first five) in anterior region.

Table No 2Total score of lateral posture grade of selected players.

\begin{tabular}{|l|l|}
\hline Badminton & 299 \\
\hline Cricket & 322 \\
\hline Hand Ball & 328 \\
\hline Throwers In Athletics & 332 \\
\hline Volly Ball & 327 \\
\hline Weight Lifters & 336 \\
\hline Power Lifters & 344 \\
\hline Body Builders & 340 \\
\hline Runners & 346 \\
\hline Swimmers & 348 \\
\hline
\end{tabular}

From the table 2, it is clear that the ambidextrous players (last five) scored more than the dexterous players (first five) in lateral region.

Table No 3 Total score of anterior and lateral posture grade of selected players.

\begin{tabular}{|l|l|}
\hline Badminton & 539 \\
\hline Cricket & 484 \\
\hline Hand Ball & 532 \\
\hline Throwers In Athletics & 509 \\
\hline Volly Ball & 537 \\
\hline Weight Lifters & 636 \\
\hline Power Lifters & 644 \\
\hline Body Builders & 640 \\
\hline Runners & 632 \\
\hline Swimmers & 648 \\
\hline
\end{tabular}

From the table 3, it is clear that the ambidextrous players (last five) scored more than the dexterous players (first five) in both anterior and lateral region.

Table No: 4 Statistical Analysis Of Data

\begin{tabular}{|l|c|l|l|l|c|}
\hline GROUP & $\mathrm{N}$ & \multicolumn{1}{|c|}{ MEAN } & STD.DEVIATION & $\mathrm{T}$ & $\begin{array}{c}\text { REQURED } \\
\text { DEXTROUS }\end{array}$ \\
\cline { 1 - 3 } & 5 & 5.2020 & 23.50957 & & \\
AMBIDEROUS & 5 & 6.4000 & 6.32456 & 11.003 & 2.015 \\
\hline
\end{tabular}

\section{Findings}

From the above tables 1 to 3 , gives an idea about the faulty posture among the dexterous and ambidextrous players. Many players would not be aware of the body posture. The $4^{\text {th }}$ table provides some ideas about the difference between the dexterous and ambidextrous players. The calculated value 11.003 is more different than the table value 2.015, so the score is significant. The repeated use of the one side of the muscle groups is definitely contributing the postural deformity. In the case of a one side player, his muscles can pull his skeletal system away from the center of gravity. This is because of that particular muscles get more strength than the other side. The postural deformity whatever the cause is not inevitable and the dexterous players have more postural deformity than the ambidextrous players. During the training period, the trainer or coach gives to the players about the postural deformity and the chance to get it. And also important that improves the athlete's knowledge in the basic biomechanics of their respective movements. 


\section{Recommendations}

Based on the findings of the study following recommendations are made;-

It can be conducted for

1. Different levels of players.

2. School children's.

3. Both sexes separately.

4. Giving corrective exercises.

5. Athlete and non-athlete.

\section{References}

[1]. Karahana Azize and N Bayraktarb, Determination of the Usage of Body Mechanics in Clinical Setting and Occurrence of Low Back Pain in Nurses, (2004)

[2]. Kreichner, Glenn , Physical Education for Elementary School Children $8^{\text {th }}$ Edition, (1992)

[3]. Kothiwala , D.B, Aplia for Making Physical Education a Subject for University Examination, Jounrnal of Physical Education and Sports, (1959)

[4]. Letts M, Shapiro L, Mulder K, Klassen O, The Windblown Hip Syndrome in Total Body Cerebral Palsy . J Pediatr Orthop, (1984). 